\title{
Virtual Tour Interaktif 360 Derajat Menggunakan Teknik Image Stitching Sebagai Media Informasi Kampus STMIK Amik Riau
}

\author{
Mardainis $^{1}$, M. Arifin ${ }^{2}$, Rahmaddeni ${ }^{3}$, Yoyon Efendi ${ }^{4}$ \\ 1,2,3,4 Program Studi Teknik Informatika STMIK Amik Riau \\ 1,2,3,4 Jl. Puwodadi Km. 10 Panam, Pekanbaru, Riau, telp. 082386543137 \\ ${ }^{1}$ mardainis@ sar.ac.id, ${ }^{2}$ m.arifin@sar.ac.id, ${ }^{3}$ rahmaddeni@sar.ac.id, ${ }^{4}$ yoyonefendi@sar.ac.id
}

\begin{abstract}
Abstrak
Salah satu strategi untuk meningkatkan pertumbuhan jumlah mahasiswa baru untuk masuk ke STMIK Amik Riau dilakukannya kegiatan sosialisasi oleh bagian promosi dan penerimaan mahasiswa baru (PPMB). Media promosi yang digunakan berupa brosur, kalender, spanduk dan baliho serta melaksanakan sosialisasi ke sekolah. Promosi secara digital juga dilakukan dengan memanfaatkan website kampus dan media sosial seperti facebook, instagram, whatsapp serta youtube. Penelitian ini memberikan ide promosi dengan penggunaan Virtual Tour dengan memanfaatkan teknologi fotografi 360 derajat dengan teknik image stitching. Langkah pertama dilakukan pemilihan beberapa lokasi yang akan ditampilkan dalam Virtual Tour yang berada dalam lingkungan kampus STMIK Amik Riau. Pemilihan lokasi dengan mempertimbangkan kebutuhan informasi yang sering dibutuhkan oleh calon mahasiswa, seperti lokasi ruang pendaftaran, ruang akademik, ruang baak, ruang perkuliahan, laboratorium, aula dan mushala beserta fasilitas lainnya. Selanjutnya dilakukan kegiatan pemotretan diberbagai lokasi kampus yang sudah dipilih sebelumnya. Beberapa foto yang sudah diambil ditiap lokasi digabungkan menjadi bidang yang besar dengan teknik stitching. Selanjutnya dibuat narasi berupa teks dan audio untuk setiap lokasi foto tersebut. Penelitian dilakukan melalui beberapa langkah mulai dari Concept, Design, Material Collecting, Assembly, Testing sampai Distribution. Dari hasil pengujian Virtual Tour ini, calon mahasiswa baru bisa mengetahui informasi kampus tanpa datang ke kampus STMIK Amik Riau.
\end{abstract}

Kata kunci: Virtual Tour, Panorama 360, MDLC, Virtual Reality, Stitching Image.

\begin{abstract}
One of the strategies to increase the growth of the number of new students to enter Amik Riau STMIK is to conduct socialization activities by the promotion and admission of new students (PPMB). Promotional media used in the form of brochures, calendars, banners and billboards as well as carrying out socialization to schools. Digital promotion is also carried out by utilizing campus websites and social media such as Facebook, Instagram, WhatsApp and YouTube. This research provides promotional ideas with the use of Virtual Tour by utilizing 360 degree photography technology with image stitching techniques. The first step is to choose several locations that will be displayed on the Virtual Tour within the Amik Riau STMIK campus environment. Site selection by considering the information needs that are often needed by prospective students, such as the location of the registration room, academic room, classroom, lecture room, laboratory, hall and prayer room along with other facilities. Next, there will be a photo shoot at various campus locations that have been previously selected. Some photos that have been taken at each location are combined into a large field with stitching techniques. Then a narration in the form of text and audio is made for each location of the photo. The study was conducted through several steps ranging from Concept, Design, Material Collecting, Assembly, Testing to Distribution. From the results of this Virtual Tour test, prospective new students can find out campus information without coming to the STMIK Amik Riau campus.
\end{abstract}

Keywords: Virtual Tour, Panorama 360, MDLC, Virtual Reality, Stitching Image. 


\section{Pendahuluan}

Pada tahun 1990 Yayasan Komputasi Riau mendirikan perguruan tinggi komputer pertama di Riau dengan nama Amik Riau jenjang pendidikan diploma tiga (D3). Selanjutnya pada tahun 1996 AMIK Riau ditingkatkan menjadi Strata Satu (S1) dengan nama STMIK Amik Riau. Saat itu STMIK Amik Riau merupakan pilihan satu satunya bagi putra putri Riau untuk melanjutkan pendidikan ke bidang ilmu komputer,sehingga penerimaan mahasiswa baru selalu ramai. Sejalan dengan waktu saat ini telah berdiri beberapa perguruan tinggi sejenis baik negeri maupun swasta. Hal ini tentu berdampak ke STMIK Amik Riau didalam penerimaan mahasiswa baru. STMIK Amik Riau harus siap bersaing dengan perguruan tinggi lain sejenis dalam penerimaan mahasiswa baru. Untuk itu STMIK Amik Riau membuat divisi promosi dan penerimaan mahasiswa baru (PPMB), hal ini pernah penulis bahas dalam jurnal sebelumnya "Penerapan Teknologi Multimedia dalam Marketing Perguruan Tinggi Swasta", 2015. Disana penulis sampaikan, bagi perguruan tinggi yang tidak memiliki tim marketing yang handal kecendrungan penerimaan mahasiswanya menurun. Untuk itu tim marketing harus mempunyai pandangan yang luas terhadap perkembangan teknologi dan mempunyai kemampuan inovasi. Salah satunya mereka juga mengusai teknologi multimedia yang dapat dimanfaatkan dalam marketing[1]. Pemanfaatan teknologi multimedia untuk marketing saat ini lebih dikenal dengan istilah digital marketing[2]. Hal ini juga pernah diteliti oleh Werner Reinartz dalam penelitiannya berjudul "The impact of digital transformation on the retailing value chain"[3].

Divisi PPMB bekerja untuk selalu menyampaikan informasi keberadaan STMIK Amik Riau ketengah masyarakat terutama calon mahasiswa baru dengan berbagai tool yang dimiliki. Tool promosi STMIK Amik Riau berupa brosur, kalender dan iklan di media cetak serta pemasangan spanduk dan baliho yang berisikan informasi mengenai STMIK Amik Riau termasuk informasi penerimaan mahasiswa baru. Tim PPMB juga turun ke lapangan dengan mengunjungi sekolah sekolah yang potensial untuk calon mahasiswa dan menyampaikan informasi kampus secara interaktif. Penggunaan website dan sosial media seperti facebook, instagram dan whatsapp juga dilakukan serta menunjuk admin untuk mengelola akun tersebut, jika ada informasi yang dibutuhkan oleh pengguna sosial media maka admin akan menanganinya. STMIK Amik Riau juga mengembangkan aplikasi robotik chatboot yang dapat menjawab informasi yang dibutuhkan oleh pengguna secara otomatis. Beberapa tahun belakangan juga digunakan akun youtube yang berisikan video kegiatan dosen dan mahasiswa serta fasilitas kampus[2]. Tim PPMB selalu mencari ide kreatif dan inovasi untuk melakukan promosi kampus[4]. Semakin mudah informasi yang dibutuhkan calon mahasiswa tentang keberadaan STMIK Amik Riau, semakin banyak mahasiswa baru masuk ke STMIK Amik Riau.

Pada penelitian ini akan dibahas metode promosi dengan menggunakan virtual tour interaktif 360 derajat menggunakan teknik image stitching. Pengunjung aplikasi bisa menjelajahi kampus STMIK Amik Riau untuk mendapatkan informasi tanpa harus datang ke kampus. Teknik image stitching memanfaatkan banyak foto foto berbagai lokasi dikampus, seperti ruang akademis, ruang dosen, ruang administrasi, ruang kelas, laboratorium serta aula. Sehingga pengunjung aplikasi ini bisa melihat lihat fasilitas kampus dan mengetahui nama dan fungsi masing masing melalui teks dan audio dari foto yang ditampilkan.

Banyak penelitian mengenai Virtual Tour yang bisa dijadikan refensi dalam penelitian ini, diantaranya dilakukan oleh Fahri R. Daud, Virginia Tulenan, Xaverius B. N. Najoan dengan judul "Virtual Tour Panorama 360 Derajat Kampus Universitas Sam Ratulangi Manado"[5]. Penelitian mengenai virtual tour juga diteliti oleh D Tri Octafian dan Herlinda Kusmiati dengan judul "Rekayasa perangkat lunak virtual tour jakabaring sport city (jsc)" pada tahun 2018[6]. Achmad Choiron dan Irfian Lesmana juga melakukan penelitian dengan judul "Aplikasi Virtual Tour Dinamis Pada Universitas Dr. Soetomo Surabaya Berbasis Web" [7]. Penelitian mengenai virtual tour juga pernah dilakukan oleh Namrata Bakre, Aditi Deshmukh, Pavitra Sapaliga, Prof. Yogesh Doulatramani dengan judul "Campus Virtual Tour" yang diterbitkan pada jurnal International Journal of Advanced Research in Computer Engineering \& Technology (IJARCET) Volume 6, Issue 4, April 2017, ISSN: 2278-1323[8]. 
Untuk menggabungkan beberapa foto yang diambil dilingkungan kampus penulis menggunakan aplikasi stitching Gear 360 Action Director (Cyberlink Learning Center), aplikasi ini membantu pengguna mengimpor dan menjahit (menyatukan) foto-foto berbasis $360^{\circ}$.

Kelebihan pada penelitian ini sistem virtual taour yang dibagun bersifat dinamis, artinya pengguna bisa menambahkan titik lokasi tertentu di STMIK Amik Riau yang ingin ditampilkan sesuai dengan kebutuhan. Titik lokasi bisa dirubah atau dihapus jika memang sudah tidak sesuai lagi dengan kebutuhan pengguna. Demikian juga dengan narasi masing masing lokasi yang ditampilkan bisa di update sesuai kebutuhan.

\section{Metode Penelitian}

Langkah dalam melakukan penelitian ini dari awal sampai akhir adalah sebagai mana yang ditampilkan pada gambar 1 .

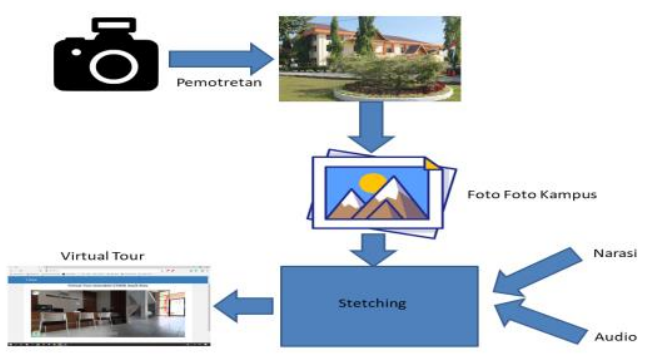

Gambar 1. Metodologi Penelitian

Langkah pertama dilakukan pemilihan beberapa lokasi yang akan ditampilkan dalam Virtual Tour yang berada dalam lingkungan kampus STMIK Amik Riau. Pemilihan lokasi dengan mempertimbangkan kebutuhan informasi yang sering dibutuhkan oleh calon mahasiswa, seperti lokasi ruang pendaftaran, ruang akademik, ruang baak, ruang perkuliahan, laboratorium, aula dan mushala beserta fasilitas lainnya. Selanjutnya dilakukan kegiatan pemotretan diberbagai lokasi kampus yang sudah dipilih sebelumnya. Beberapa foto yang sudah diambil disatu lokasi digabungkan menjadi bidang yang besar dengan teknik stitching. Selanjutnya dibuat narasi berupa teks dan audio untuk setiap lokasi foto tersebut.

Untuk pedoman dalam melaksanakan penelitian ini digunakan metode Multimedia Development Life Cysle (MDLC)[9]. Pada tahap Concept direncanakan membuat media promosi yang interaktif berbasis virtual tour. Selanjutnya pada fase Design dibuat rancangan virtual tour STMIK Amik Riau dengan membuat disain interface untuk masing masing lokasi. Pada fase Material Collecting dilakukan pemotretan untuk setiap lokasi yang sudah ditetapkan. Fase selanjutnya adalah Assembly dengan melakukan penyambungan (Stitching) gambargambar yang sudah dikumpulkan menjadi gambar panorama yang luas dan memasangnya dalam aplikasi virtual tour. Selanjunya dilakukan Testing dengan menguji sistem virtual tour yang dibuat, memastikan setiap fitur berfungsi sebagaimana mestinya. Terakhir fase Distribution dimana sistem yang dibangun dipasang dalam web kampus sehingga bisa diakses oleh pengguna. Tahap tersebut dapat dilihat dalam gambar 2 .

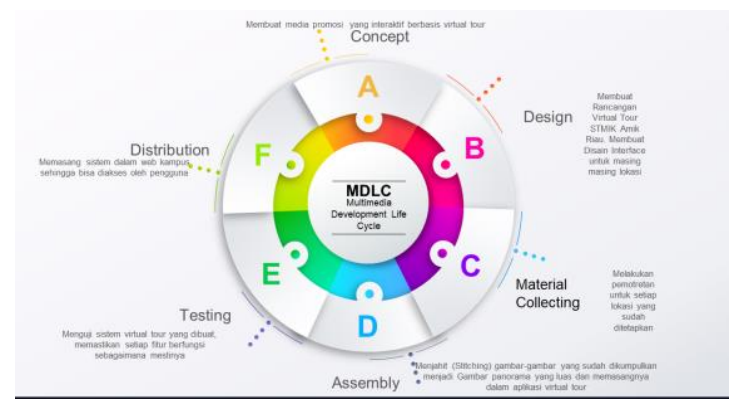

Gambar 2. Metode Penelitian MDLC 
Enam langkah MDLC yang diterapkan dalam penelitian ini :

\section{Concept.}

Pada tahap konsep dilakukan perancangan membuat virtual tour yang akan digunakan sebagai media promosi kampus STMIK Amik Riau. Perancangan system menggunakan tool UML (use case diagram dan activity diagram) dengan membuat desain global dan desain terinci. Dalam perancangan global membahas use case diagran dan activity diagram.

\section{Diagram Use Case (Use Case Diagram)}

Use case diagram menampilkan aktor yang dapat mengakses use case didalam system virtual tour yang dibangun. Pada gambar 3. Aktor tersebut berperan sebagai admin dan sebagai pengunjung.

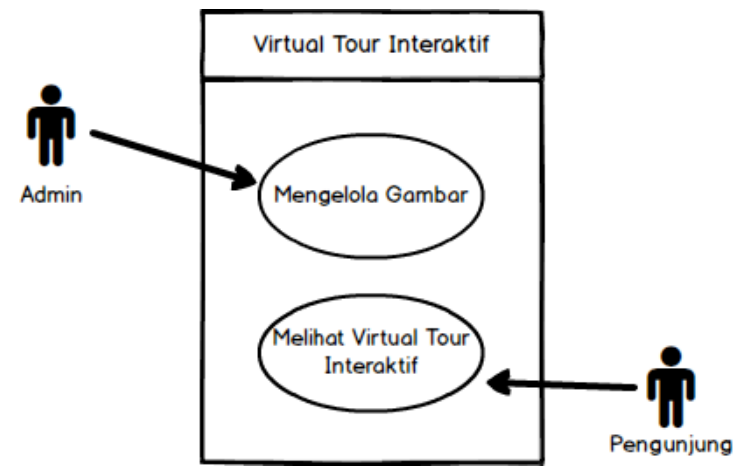

Gambar 3. Use Case Diagram

Tabel 1. Tabel Mengelola Gambar

\begin{tabular}{cl}
\hline Aktor & \multicolumn{1}{c}{ Keterangan } \\
\hline Admin & $\begin{array}{l}\text { Admin dapat mengelola virtual tour baik dalam menambah spot, } \\
\text { mengurangi maupun melakukan update pada sistem. }\end{array}$
\end{tabular}

Tabel 2. Tabel Virtual Tour

\begin{tabular}{cc}
\hline Aktor & Keterangan \\
\hline Pengunjung & Pengunjung melihat virtual tour interaktif STMIK Amik Riau.
\end{tabular}

\section{Activity Diagram}

Activity Diagram dibawah ini menggambarkan alur

Kegiatan admin dalam mengelola virtual tour ditampilkan pada gambar 2 berikut :

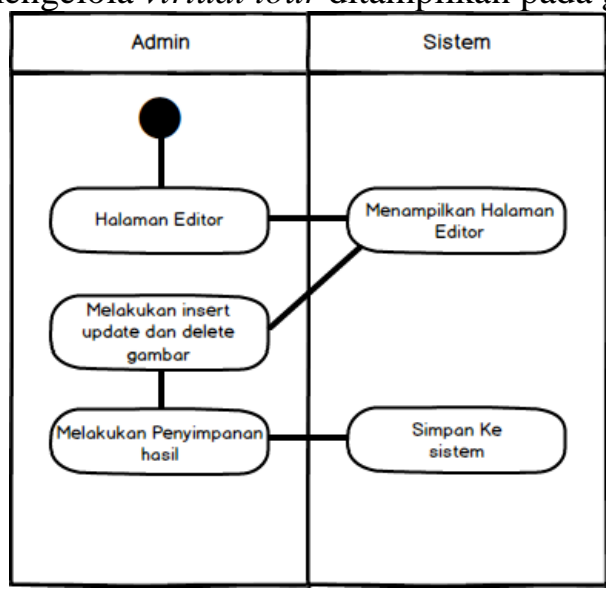

Gambar 4. Activity Diagram Mengelola Gambar 


\section{Desain Terinci}

Pada tahap ini dilakukan rancangan virtual tour dengan mengikuti denah kampus STMIK Amik Riau. Beberapa lokasi bisa disajikan dalam virtual tour yang dibuat.

\section{Titik Pengambilan foto panorama kampus STMIK Amik Riau}

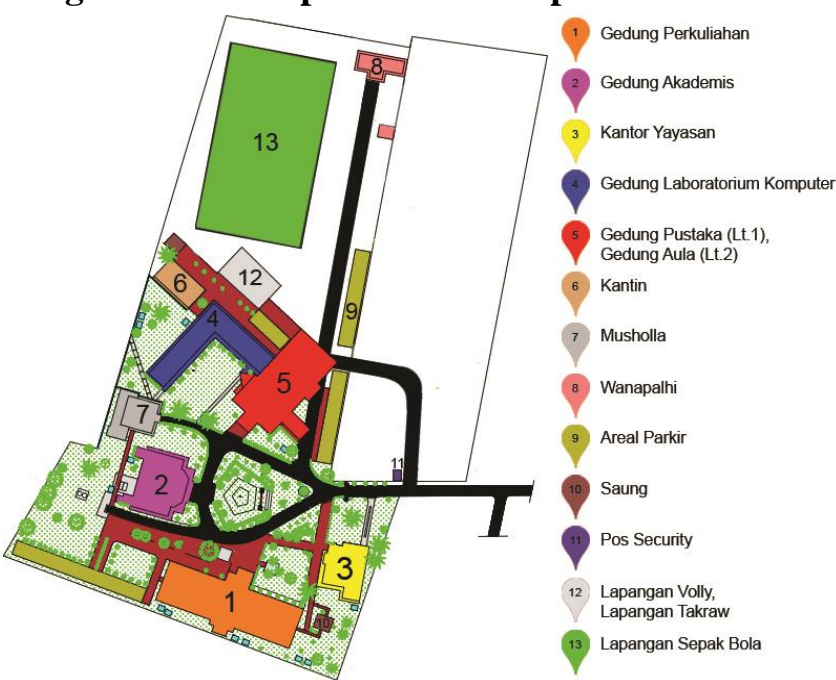

Gambar 5. Denah Kampus STMIK Amik Riau.

Dari denah diatas dapat dijelaskan rencana pengambilan foto disetiap lokasi seperti yang diuraikan berikut :

1. Gedung A (Akademis)

Pengambilan gambar dilakukan di 5 titik yaitu 1 titik didepan gedung, 3 titik di dalam gedung akademis dan 1 titik di belakang Gedung akademis.

2. Gedung B (Laboratorium)

Pengambilan gambar di gedung B terdapat 13 titik, dimana 7 titik didalam laboratorium (Multimedia, Mobile 1, programming 1, programming 2, networking), 5 titik di luar laboratorium yaitu dilapangan depan laboratorium multimedia, tangga laboratorium, depan laboratorium programming 2 dan depan laboratorium networking.

3. Gedung C (Perpustakaan dan YKR Convention Hall)

Pada perpustakaan dilakukan pengambilan gambar pada 5 titik. 2 titik di depan perpustakaan dan 2 titik didalam perpustakaan serta 1 titik di depan YKR Convention Hall.

4. Gedung D (Gedung Perkuliahan, BAAK, dan Pendaftaran)

Pada lokasi ini dilakukan pengambilan gambar pada 16 titik. 1 titik didepan gedung D, 1 titik didepan BAAK dan Pendaftaran, dan 14 titik pengambilan dilakukan sepanjang gedung D.

5. Gedung E (LPPM, Sistem Informasi, Pemasaran dan Penerimaan Mahasiswa Baru) Di gedung E dilakukan pengambilan gambar dari 2 titik lokasi, 1 titik didepan Gedung $\mathrm{E}$ dan 1 titik di dalam Gedung E.

6. Gedung F (Kantor Yayasan, BEM, dan Unit Usaha)

Pada lokasi ini dilakukan pengambilan gambar dari 2 titik lokasi, 1 titik didepan kantor Yayasan dan 1 titik didepan BEM.

7. Lainnya (Mushalla, Parkiran, Lapangan Volly dan takraw, Lapangan Bola, Wanapalhi, kantin dan taman).

\section{Design.}

Pada tahap disain Pembuatan Virtual Tour Panorama digunakan aplikasi Pano2VR versi 6.0.3. dengan langkah-langkah pembuatan sebagai berikut :

1. Masukan gambar panorama yang telah dibuat kedalam aplikasi dengan pilih menu "Input". 
Pano2VR pro 6.03 - 64bit

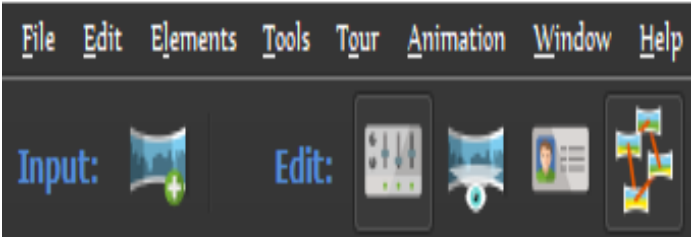

Gambar 6. Menu Input Pano2VR

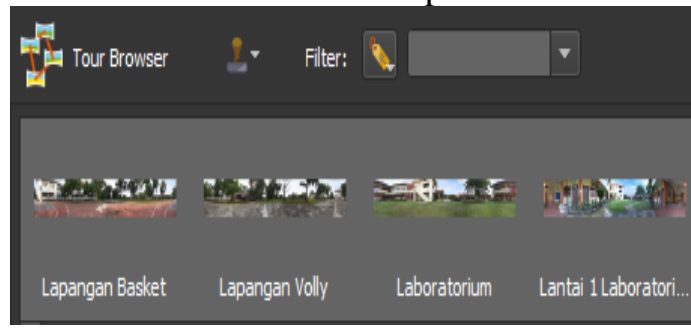

Gambar 7. Tampilan Tour Browser

2. Langkah setelah memasukan bahan adalah mengatur hasil keluaran yang di inginkan, disini penulis menggunakan keluaran berupa HTML5, karena akan digunakan pada website seperti terlihat pada gambar 11 .

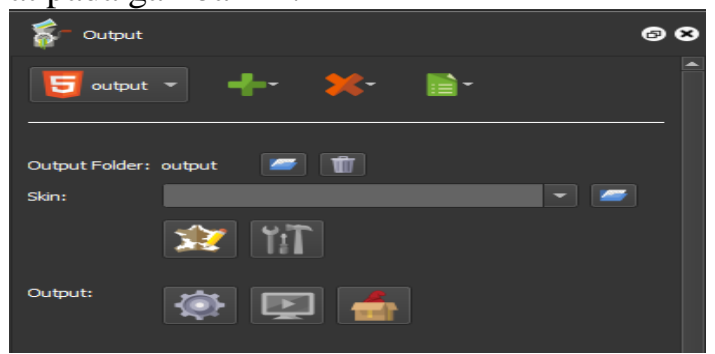

Gambar 8. Menu Output Pano2VR

3. Untuk dapat membuat virtual tour maka harus membuat hotspot yang berfungsi sebagai titik gerak dari tiap bagian virtual tour.

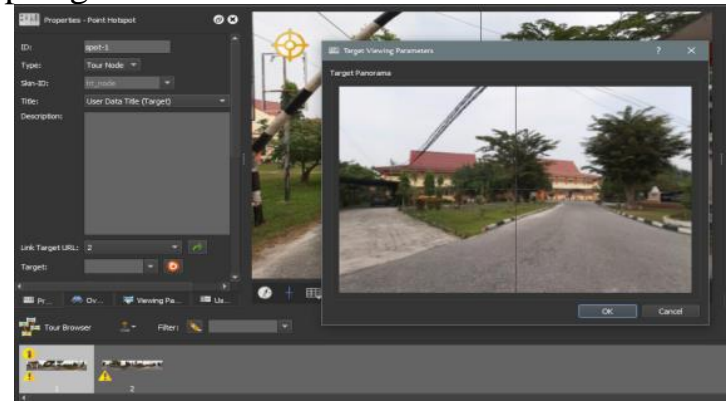

Gambar 9. Membuat Hotspot dan Target Viewing Pano2VR

Lalu buat judul dari gambar panorama yang di tambahkan seperti pada gambar 14 .

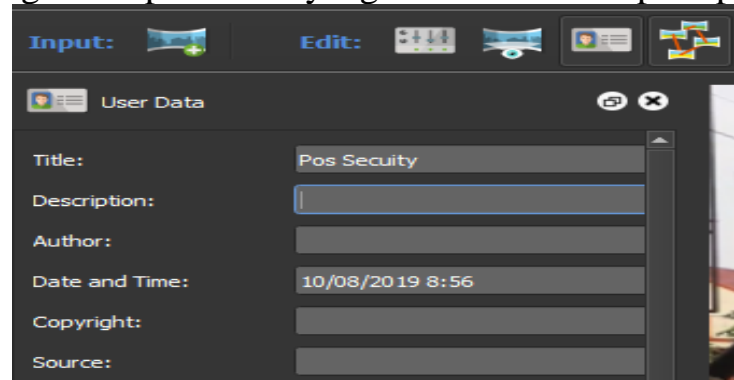

Gambar 10. Pemberian judul gambar panorama 
4. Setelah membuat hotspot dan semua gambar telah disatukan dalam tour browser maka selanjutnya adalah melakukan pembuatan skin dari virtual tour, seperti pada gambar 15 .

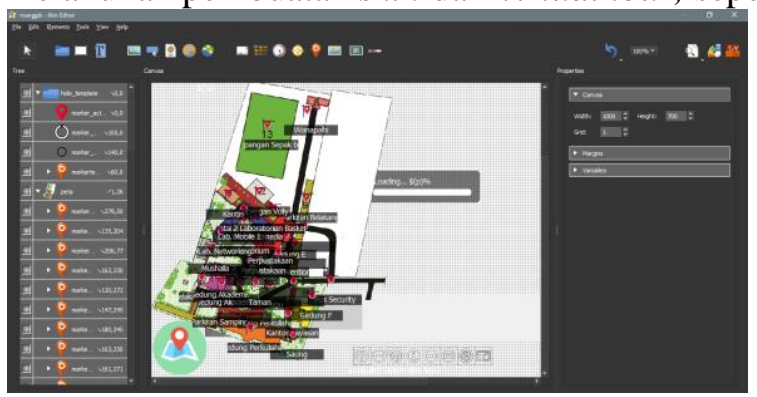

Gambar 11. Proses edit di skin editor

5. Untuk menambahkan map pada virtual tour pilih menu "Tour Map" dan masukan map yang akan digunakan. Dimana kita menggunakan floorplan sebagai map tour, seperti pada gambar 16

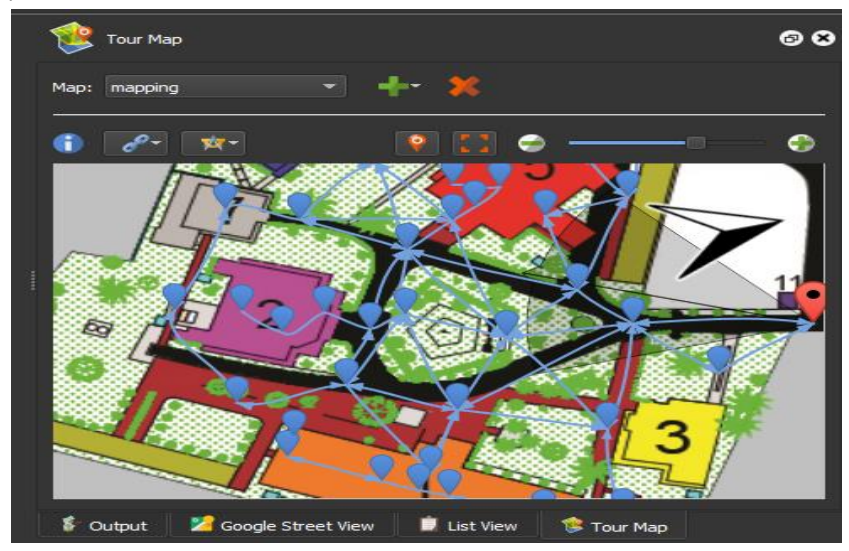

Gambar 12. Proses menambahkan map dan spot

6. Melakukan eksport file dengan format Garden Gnome Software Package (.ggpkg). Selanjutnya untuk membuat website virtual tour digunakan wordpress sebagai CMS (Content Management System).

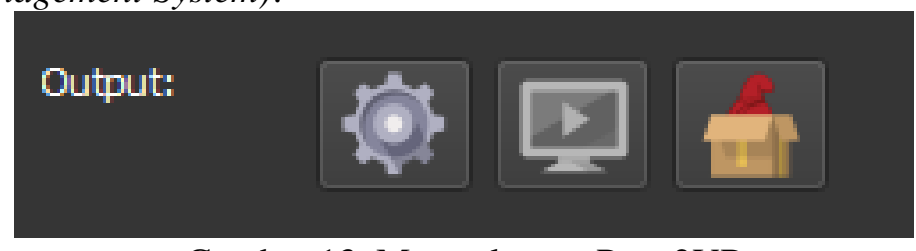

Gambar 13. Menu eksport Pano2VR

Desain Output Virtual Tour berisikan rancangan tampilan sistem virtual tour mulai dari halaman utama dan halaman admin. Berikut bentuk tampilan halaman utama virtual tour :

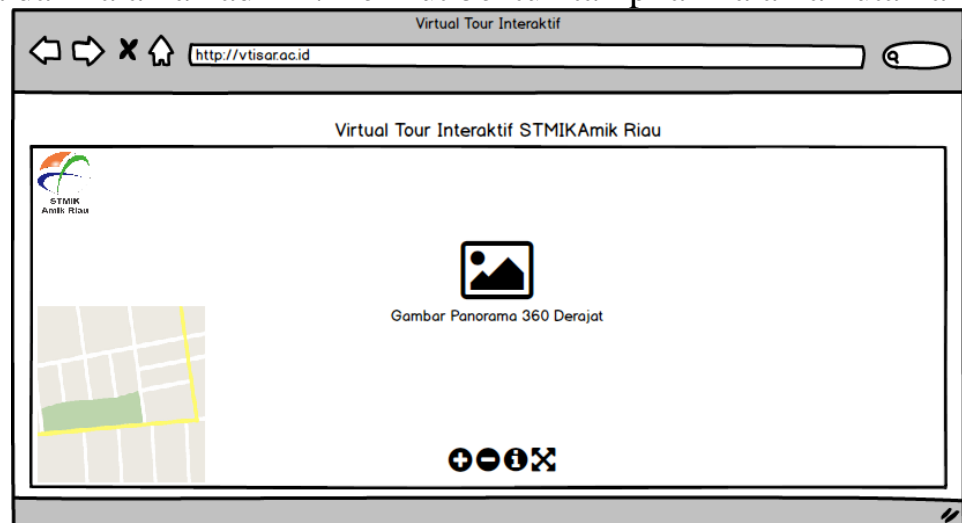

Gambar 14. Halaman Utama Virtual Tour 
Gambar 18 merupakan gambar desain output untuk Halaman utama sistem yang akan di bangun. Terdapat tombol map pada menu utama digunakan untuk melihat peta dari STMIK Amik Riau. Jadi dengan memilih peta maka kita dapat menjelajahi kampus STMIK Amik Riau sesuai lokasi yang dipilih.

Desain Menu Virtual Tour

Pada tabel 3 virtual tour yang akan digunakan terdapat beberapa menu yang akan tampil pada gambar panorama dan menu map.

Tabel 3. Menu Virtual Tour

\begin{tabular}{|c|c|c|}
\hline Nama & Simbol & Deskripsi \\
\hline Zoom In & & Memperbesar ukuran panorama \\
\hline$\underline{\text { Zoom Out }}$ & & Memperkecil ukuran panorama \\
\hline Show User Data & & Menunjukan informasi panorama \\
\hline Full Screen & & Menu tampilan penuh \\
\hline Zoom In & + & Memperbesar ukuran map \\
\hline Zoom Out & - & Memperkecil ukuran map \\
\hline Spot & & Untuk berpindah view point \\
\hline Image & $\therefore$ & Menampilkan gambar/foto \\
\hline Logo & 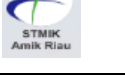 & Logo virtual tour \\
\hline
\end{tabular}

Proses penggabungan beberapa foto dilakukan dengan memperhatikan kemiripan foto sebelumnya dengan foto berikutnya agar apabila digabungkan terlihat foto tersebut jadi menyambung[10].

3. Material Colecting.

Material Colection dilakukan dengan melakukan pemotretan gambar. Untuk melakukan pengambilan gambar maka dilakukan pemotretan dibeberapa lokasi dalam kampus dengan memanfaatkan teknologi digital[11]. Pedoman dalam pemotretan sebagai berikut :

1. Pemotretan dilakukan dalam kondisi cuaca cerah agar hasil pemotretan bagus. Sebaiknya dilakukan sekitar jam 12 sampai jam 2 siang untuk agar efek bayangan dari berbagai obyek bisa dikurangi.

2. Pada saat pemotretan panorama, pergerakan kamera sebaiknya menggunakan tripod agar gambar yang dihasilkan tidak goyang.

3. Untuk menjahit atau menggabungkan beberapa gambar menjadi lebih sempurna dalam sebuah lokasi, setiap gambar diharuskan memiliki kesamaan antara 25\% sampai $75 \%$, sehingga proses penyambungannya lebih alami dan tidak terlihat batasannya dan bisa dilihat secara horizontal $360^{\circ}$ [12].

4. Dalam melakukan pemotretan panorama, dimulai dari kiri kekanan, selanjutnya dari atas ke bawah, kemudian ditambah masing-masing satu foto untuk penglihatan paling atas dan paling bawah.

5. Waktu pemotretan antara satu foto dengan foto berikutnya dalam satu lokasi sekitar dua hingga lima detik agar tidak adanya perubahan terlalu besar antar foto yang diambil[13].

6. Simpan semua foto tiap lokasi di media penyimpanan cadangan agar jangan hilang atau terhapus. 


\section{Assembly}

Padada tahap Assembly dilakukan penjahitan gambar panorama dengan bantuan aplikasi penjahitan gambar (image stitching) seperti Adobe Photoshop CC 2019 secara otomatis. Langkah penjahitan sebagai berikut :

1. Buka aplikasi Adobe Photoshop CC 2019 kemudian pilih menu "File" selanjutnya pilih "Automate". Kemudian pilih "Photomerge".

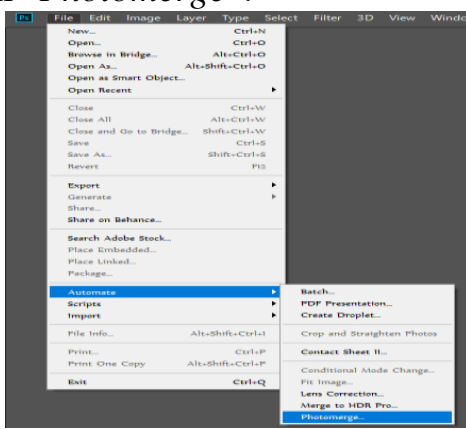

Gambar 15 Tampilan Untuk Memilih Menu Photomerge

2. Kemudian pada tampilan Photomerge terdapat beberapa model pilihan yang dapat kita gunakan yaitu Auto, Perspective, Cylindrical, Spherical, Collage, Reposition.

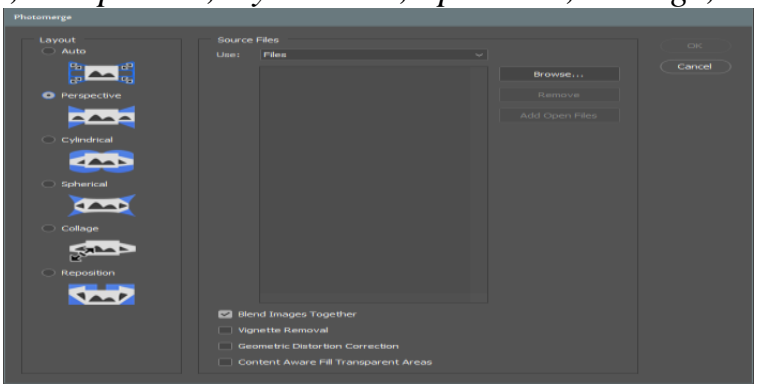

Gambar 16 Berbagai Model Layout Photomerge

3. Masukan gambar yang telah diambil, kemudian lakukan stitching pada gambar seperti ditampilkan pada gambar 17 .

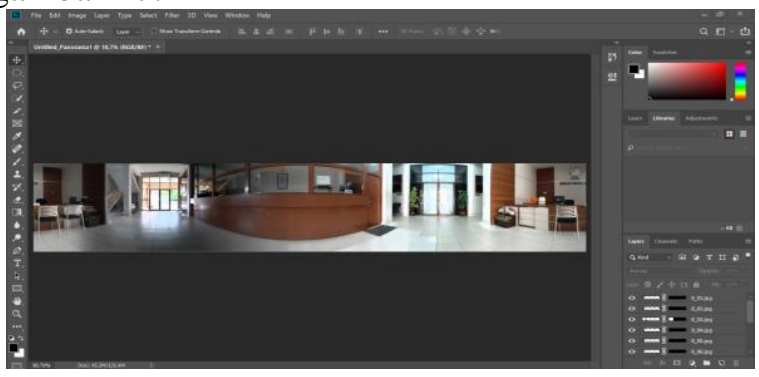

\section{Testing}

Gambar 17 Hasil Photomerge

Testing dilakukan dengan metode Black Box, pengujian dilakukan untuk setiap fitur yang ada dalam sistem. Hasil testing dapat dilihat pada bagian bawah point 3.2.

\section{Distribution.}

Agar sistem Virtual Tour ini bisa diakses oleh calon mahasiswa maka sistem virtual tour akan di pasang dalam website STMIK Amik Riau.

\section{Hasil dan Pembahasan}

\subsection{Tampilan Sistem} berikut :

Bentuk tampilan sistem Virtual Tour STMIK Amik Riau pada saat dijalankan sebagai

1. Halaman Utama

Halaman utama sistem bisa disajikan seperti gambar 19. Dalam visual ditampilkan map yang bisa diklik oleh pengguna. 


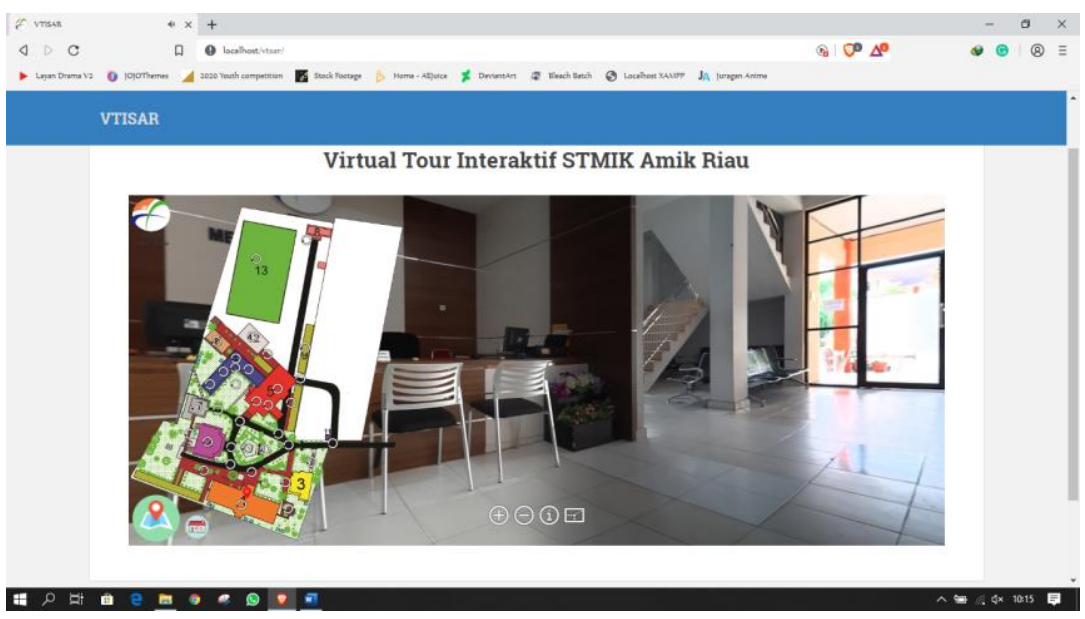

Gambar 18. Tampilan Menu Utama Virtual Tour Interaktif

Untuk memilik lokasi yang diinginkan informasinya, pengguna bisa memilih melalui menu atau di klik pada map kampus yang ditampilkan.

2. Halaman Admin

Halaman admin menggunakan Wordpress sebagai CMS (Content Management System) yang dapat dilihat pada gambar 19. Digunakan untuk menampilkan (posting) virtual tour menggunakan Garden Gnome Package pada wordpress, seperti pada gambar 19. Proses input gambarnya ditampilkan pada gambar 20.

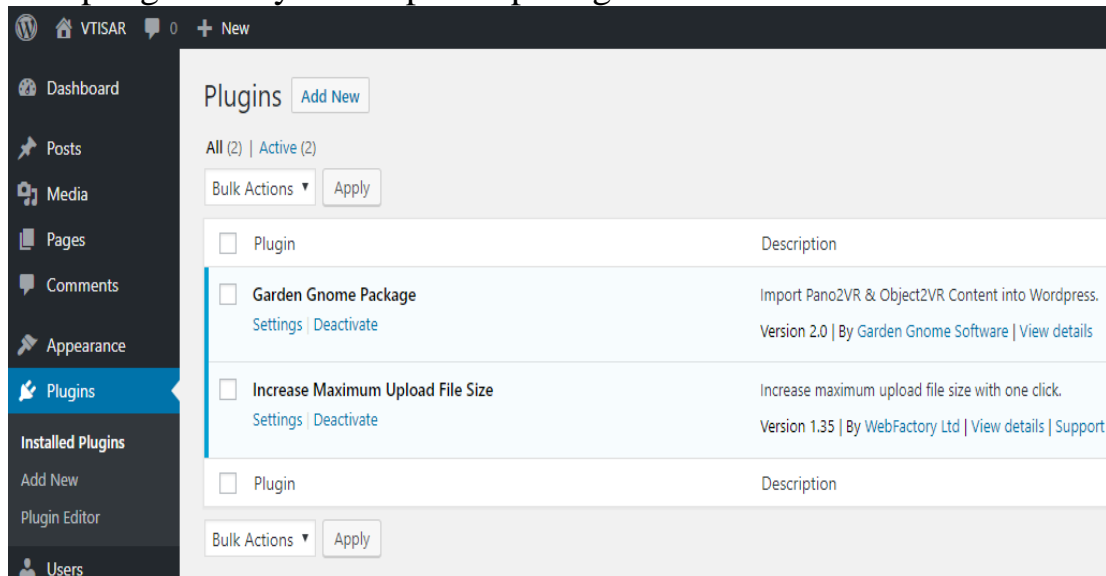

Gambar 19. Plugin Garden Gnome Package Terpasang

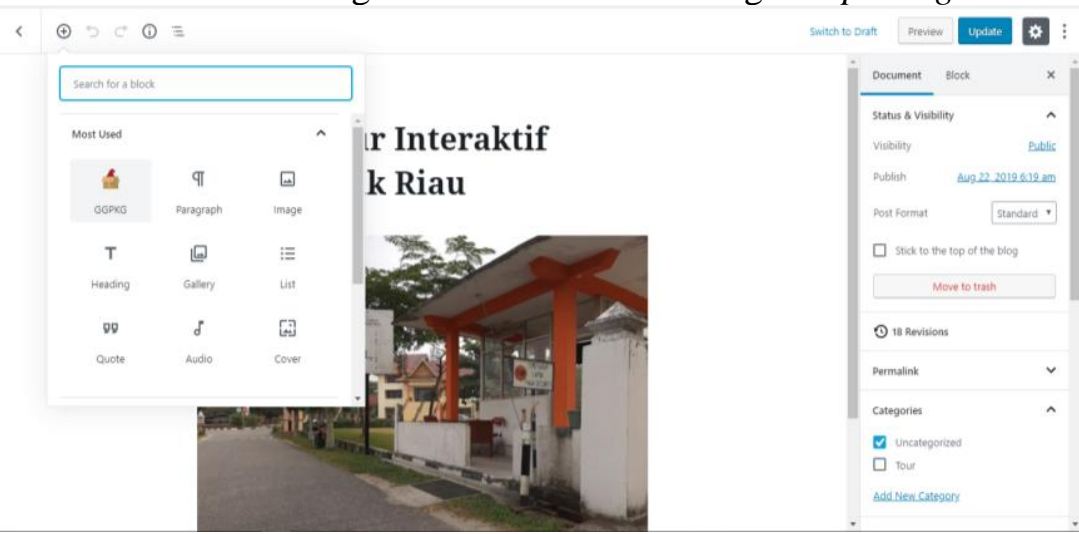

Gambar 20. Tampilan Proses Input Virtual Tour

3. Pengaturan Keluaran (Layout) Virtual Tour

Untuk membuat tampilan yang lebar dan tanpa sidebar maka pengaturan dapat dilakukan di menu "Customize" seperti terlihat pada gambar 21. 


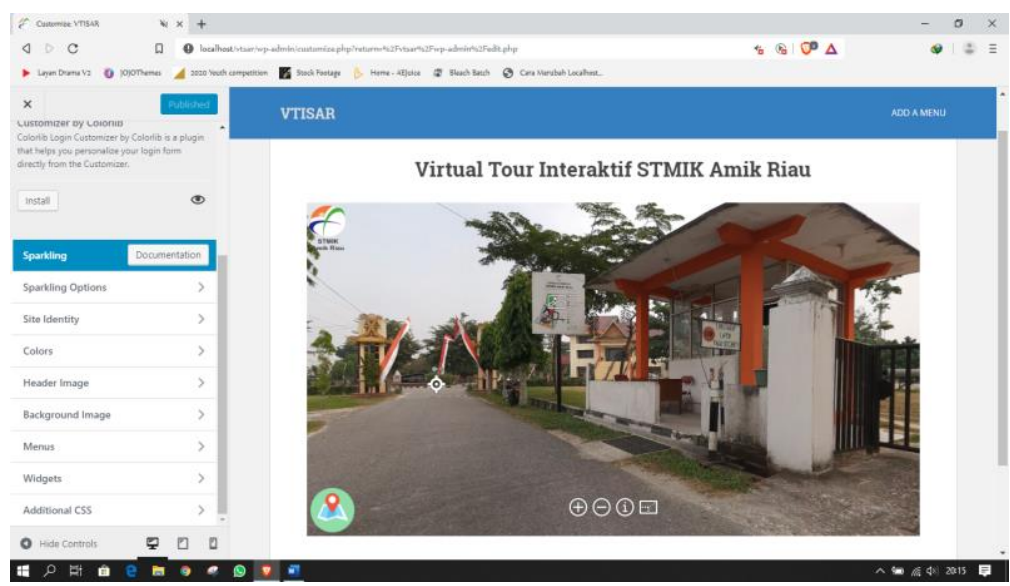

Gambar 21. Tampilan Pengaturan Layout Virtual Tour

4. Tampilan Mode Full Screen Virtual Tour

Dalam tampilan layar penuh (Full Screen) tampilan dari virtual tour dapat dilihat pada gambar 22.

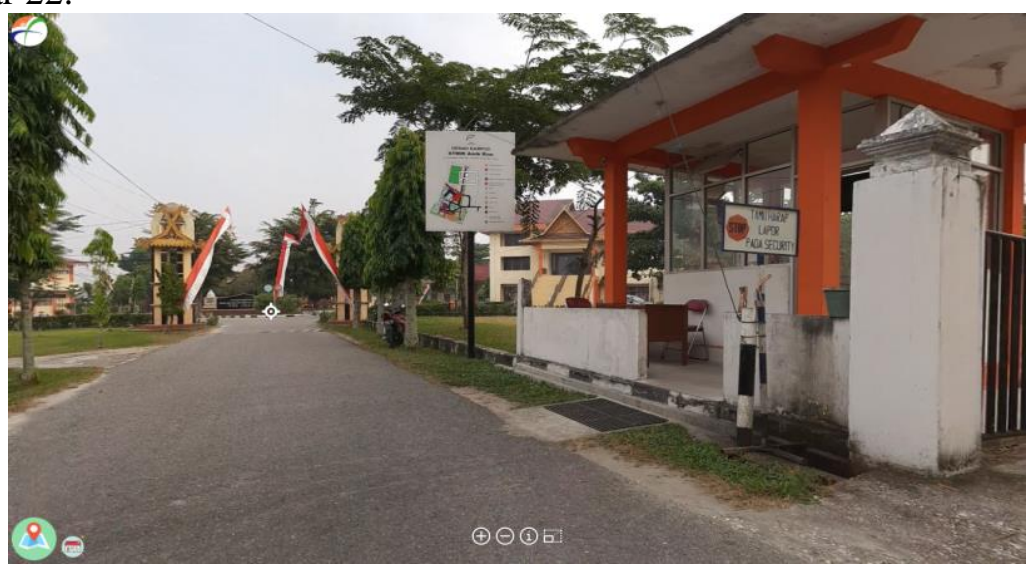

Gambar 22. Tampilan Layar Penuh Virtual Tour

\subsection{Hasil Pengujian}

Selanjutnya dilakukan pengujian sistem virtual tour dengan teknik black box, black box testing merupakan teknik pengujian perangkat lunak yang fokus pada spesifikasi fungsional dari perangkat lunak[14],[15]. Tujuan pengujian adalah untuk melihat sistem yang dibangun apakah semua berjalan dengan baik atau tidak dan dari hasil pengujian dapat dijelaskan pada tabel 4 berikut ini :

Tabel 4. Pengujian Black Box

\begin{tabular}{|c|c|c|c|c|}
\hline Deskripsi & Masukan & Kriteria Evaluasi & Hasil Pengujian & Kesimpulan \\
\hline $\begin{array}{l}\text { Tampil nama } \\
\text { titik } \\
\text { pengelihatan }\end{array}$ & $\begin{array}{l}\text { Akses } \\
\text { wilayah } \\
\text { Gambar } \\
\text { pratinjau } \\
\text { titik } \\
\text { penglihatan }\end{array}$ & $\begin{array}{l}\text { Tampil nama } \\
\text { titik penglihatan } \\
\text { berdasarkan } \\
\text { pilihan }\end{array}$ & $\begin{array}{l}\text { Menampilkan } \\
\text { nama titik } \\
\text { penglihatan sesuai } \\
\text { gambar yang } \\
\text { didekati }\end{array}$ & $\begin{array}{l}{[\sqrt{ }] \text { Berhasil }} \\
{[\quad] \text { Tidak }} \\
\text { Berhasil }\end{array}$ \\
\hline $\begin{array}{l}\text { Tampil } \\
\text { halaman } \\
\text { Virtual Tour }\end{array}$ & $\begin{array}{l}\text { Klik salah } \\
\text { satu gambar } \\
\text { pratinjau } \\
\text { titik } \\
\text { penglihatan. }\end{array}$ & $\begin{array}{l}\text { Tampil halaman } \\
\text { Virtual tour } \\
\text { berdasarkan } \\
\text { pilihan pratinjau }\end{array}$ & $\begin{array}{l}\text { Menampilkan } \\
\text { halaman Virtual } \\
\text { tour sesuai } \\
\text { pratinjau yang } \\
\text { Dipilih }\end{array}$ & $\begin{array}{l}{[\sqrt{ }] \text { Berhasil }} \\
{[\quad] \text { Tidak }} \\
\text { Berhasil }\end{array}$ \\
\hline
\end{tabular}




\begin{tabular}{|c|c|c|c|c|}
\hline Deskripsi & Masukan & Kriteria Evaluasi & Pengujian & Kesimpulan \\
\hline $\begin{array}{l}\text { Gambar } \\
\text { panorama } \\
\text { berganti } \\
\text { dengan } \\
\text { gambar } \\
\text { panorama } \\
\text { yang dipilih }\end{array}$ & $\begin{array}{l}\text { Klik salah } \\
\text { satu gambar } \\
\text { titik } \\
\text { penglihatan } \\
\text { pada peta. }\end{array}$ & $\begin{array}{l}\text { Gambar panorama } \\
\text { berganti dan tampil } \\
\text { gambar panorama } \\
\text { berdasarkan pilihan }\end{array}$ & $\begin{array}{l}\text { Menampilkan } \\
\text { gambar } \\
\text { Panorama sesuai } \\
\text { gambar titik } \\
\text { penglihatan yang } \\
\text { dipilih }\end{array}$ & $\begin{array}{l}{[\sqrt{ }] \text { Berhasil }} \\
{[\quad] \text { Tidak }} \\
\text { Berhasil }\end{array}$ \\
\hline $\begin{array}{l}\text { Fungsi } \\
\text { tombol zoom } \\
\text { in, zoom out, } \\
\text { info dan } \\
\text { fullscreen } \\
\text { berfungsi }\end{array}$ & $\begin{array}{l}\text { Klik semua } \\
\text { tombol } \\
\text { secara } \\
\text { bergantian }\end{array}$ & $\begin{array}{l}\text { Tombol berfungsi } \\
\text { seperti fungsi } \\
\text { seharusnya }\end{array}$ & $\begin{array}{l}\text { Tombol berhasil } \\
\text { berfungsi dengan } \\
\text { baik dan sesuai } \\
\text { fungsinya }\end{array}$ & $\begin{array}{l}{[\sqrt{ }] \text { Berhasil }} \\
{[\quad] \text { Tidak }} \\
\text { Berhasil }\end{array}$ \\
\hline $\begin{array}{l}\text { Map sesuai } \\
\text { dengan lokasi } \\
\text { yang sedang } \\
\text { dibuka }\end{array}$ & $\begin{array}{l}\text { Klik salah } \\
\text { satu titik } \\
\text { pada peta }\end{array}$ & $\begin{array}{l}\text { Titik pada peta } \\
\text { sesuai dengan yang } \\
\text { ada di virtual tour }\end{array}$ & $\begin{array}{l}\text { Titik penglihatan } \\
\text { sesuai dengan } \\
\text { yang ada di peta }\end{array}$ & $\begin{array}{l}{[\sqrt{ }] \text { Berhasil }} \\
{[\quad] \text { Tidak }} \\
\text { Berhasil }\end{array}$ \\
\hline
\end{tabular}

\section{Hasil dan Pembahasan.}

Setelah dilakukan pengujian terhadap sistem virtual tour yang dibuat, semua menu navigasi dalam sistem dapat berjalan dengan baik. Sistem ini dapat digunakan sebagai media promosi untuk menyampaikan informasi kampus STMIK Amik Riau kepada calon mahasiswa. Melalui sistem virtual tour ini bisa dilihat fasilitas yang dimiliki kampus seperti gedung akademik, ruang kelas untuk perkuliahan, gedung administrasi, perpustakaan, laboratorium dan fasilitas umum lainnya. Tampilan setiap lokasi yang disajikan berupa foto panorama $360^{\circ}$. Informasi yang akan disampaikan baik foto dan narasi bisa diupdate sesuai dengan kebutuhan promosi STMIK Amik Riau. Dengan adanya sistem ini calon mahasiswa tanpa datang langsung ke kampus STMIK Amik Riau bisa melihat fasilitas dan informasi mengenai STMIK Amik Riau. Sistem yang dibangun dapat meningkatkan penyebaran informasi penerimaan mahasiswa baru dan meningkatkan minat calon mahasiswa untuk kuliah di STMIK Amik Riau. Agar mudah diakses calon mahasiswa sebaiknya link sistem dipasangkan dalam website STMIK Amik Riau.

\section{Kesimpulan}

Setelah dilakukan pengujian terhadap sistem virtual tour yang dibuat, dapat diambil kesimpulan bahwa sistem ini dapat digunakan sebagai media promosi disamping tool promosi yang sudah ada. Dengan adanya sistem ini informasi STMIK Amik Riau informasi penerimaan mahasiswa lebih mudah diperoleh calon mahasiswa. Sistem ini akan lebih baik jika dikaitkan dengan website STMIK Amik Riau sehingga lebih mudah pengguna untuk masuk mengaksesnya.

\section{Daftar Pustaka}

[1] Mardainis, "Penerapan Teknologi Multimedia dalam Marketing Perguruan Tinggi Swasta Mardainis," SATIN - Sains dan Teknol. Inf., vol. 1 No. 2, pp. 90-96, 2015.

[2] F. Guna, "Perancangan video iklan berbasis multimedia marketing di media sosial youtube dengan menggunakan sony vegas 13.0 dan adobe after effect cc tentang café tersebut dan belum menggambarkan sepenuhnya mengenai keunggulan produk dari Bvgil Gelato," pp. 390-394, 2018. 
[3] W. Reinartz, N. Wiegand, and M. Imschloss, "The impact of digital transformation on the retailing value chain," Int. J. Res. Mark., vol. 36, no. 3, pp. 350-366, 2019.

[4] M. Jamaris, "SATIN - Sains dan Teknologi Informasi Analysis untuk Menentukan Minat Calon Mahasiswa Masuk," vol. 5, no. 2, 2019.

[5] F. R. Daud, V. Tulenan, and X. B. N. Najoan, "Virtual Tour Panorama 360 Derajat Kampus Universitas Sam Ratulangi Manado," J. Tek. Inform., vol. 8, no. 1, 2016.

[6] D. T. Octafian and H. Kusmiati, "Rekayasa Perangkat Lunak Virtual Tour Jakabaring Sport City ( Jsc )," vol. 4, pp. 1-7, 2018.

[7] A. Choiron, "Aplikasi Virtual Tour Dinamis Pada Universitas Dr. Soetomo Surabaya Berbasis Web," J. Inf., vol. 2, no. 2, 2017.

[8] N. Bakre, A. Deshmukh, and P. Y. D. Pavitra Sapaliga, "Campus Virtual Tour," nternational J. Adv. Res. Comput. Eng. Technol., vol. 6, no. 4, pp. 444-448, 2017.

[9] M. Hartono, A. G. Santoso, C. L. Raya, B. Yulianto, and S. Suwarno, "Audio Visual Media Components in Educational Game for Elementary Students," ComTech Comput. Math. Eng. Appl., vol. 7, no. 4, p. 255, 2016.

[10] G. Yuda Pramana, "Penerapan metode image stitching pada pembuatan virtual reality pengenalan islamic center universitas ahmad dahlan," JIKO (Jurnal Inform. dan Komputer), vol. xx, pp. 1-8, 2019.

[11] A. S. A. Purnomo, "Fotografi Di Era Media Sosial: Studi 'Toko Memorabilia' Karya Agan Harahap," J. Bhs. Rupa, vol. 1, no. 2, pp. 81-88, 2018.

[12] H. Tjiang, 7 Hari Belajar Fotografi Dengan Langkah Mudah Praktis Dan Lengkap, 1st ed. Jakarta : Elex Media Komputindo, 2015.

[13] D. S. Photography, Essential Guide to Landscape Photography. Dennis Publishing, 2015.

[14] A. Krismadi, A. F. Lestari, A. Pitriyah, I. W. P. A. Mardangga, M. Astuti, and A. Saifudin, "Pengujian Black Box berbasis Equivalence Partitions pada Aplikasi Seleksi Promosi Kenaikan Jabatan,” J. Teknol. Sist. Inf. dan Apl., vol. 2, no. 4, p. 155, 2019.

[15] T. S. Jaya, "Pengujian Aplikasi dengan Metode Blackbox Testing Boundary Value Analysis (Studi Kasus: Kantor Digital Politeknik Negeri Lampung)," J. Inform. Pengemb. IT, vol. 3, no. 2, pp. 45-46, 2018. 